\title{
Selectively advantageous effects of $B$ chromosomes on germination behaviour in Allium schoenoprasum L.
}

\author{
A. B. PLOWMAN \& S. M. BOUGOURD* \\ Department of Biology, University of York, York YO1 5DD, U.K.
}

\begin{abstract}
The effects of B chromosomes in Allium schoenoprasum on germination rate and on the ability of seeds to germinate under drought conditions have been investigated. When water was freely available for germination, there was an increased frequency of B-containing individuals amongst the first 10 per cent of seeds to germinate compared with the middle germinating group ( $64 \mathrm{cf}$. 56 per cent). Two drought regimes were employed: in one ('droplet') seeds were provided with a limited amount of water, and in the other ('PEG') the availability of water was limited osmotically. There was a significantly increased frequency of B-containing individuals amongst the 5 per cent of seeds that were able to germinate in both the droplet sample (79 per cent) and the PEG sample (65 per cent) compared with the control sample (56 per cent). Although the early and drought germinating groups had higher frequencies of B-containing seedlings, the individual seedlings did not carry a significantly increased number of $\mathrm{B}$ chromosomes. The increases in the frequencies of B-containing seedlings in the early and drought germinating groups were comparable to or greater than that observed previously in the wild between the seed and seedling stages, suggesting that the increased survival of B-containing individuals in natural populations could be due to the effects of Bs on germination behaviour. There was no relationship between the presence of B chromosomes and seed size, seed density or seed shape, implying that differences in these seed characteristics do not provide an explanation of the effects of $\mathrm{B}$ chromosomes on germination.
\end{abstract}

Keywords: Allium schoenoprasum, B chromosomes, drought, fitness, germination, seed size.

\section{Introduction}

Supernumerary B chromosomes are one of the most common forms of naturally occurring chromosomal polymorphisms (Jones \& Rees, 1982). Their role in the genetic system has been the subject of debate for many years (Darlington, 1956; Jones, 1975; Jones \& Rees, 1982). The commonly held view is that B chromosomes are selfish, persisting in populations as parasitic chromosomes by virtue of accumulation mechanisms despite the decreased fitness of B-containing individuals (Jones, 1985). However, there are two observations that argue against such an extreme view. First, there are significant numbers of species, including Centaurea scabiosa (Fröst, 1958), Guizotia scabra (Hiremath \& Murthy, 1986) and Poa alpina

*Correspondence.
(Håkansson, 1954), in which B chromosome accumulation does not occur; in some cases a substantial loss of Bs during transmission has been reported (e.g. Anthoxanthum alpinum, Rozmus, 1963). Since arguments for parasitic B chromosomes rely on the operation of accumulation mechanisms to explain their persistence (Green, 1990), B chromosomes in species which lack such mechanisms cannot be considered to be parasitic. Secondly, and contrary to the assertion that attempts at ascribing an adaptive role in Bs have been singularly unsuccessful (Jones, 1991), there are a number of convincing reports that B chromosomes can enhance the fitness of their hosts (Rees \& Hutchinson, 1973; Hutchinson, 1975; Teoh et al., 1976; Teoh \& Jones, 1978; Holmes \& Bougourd, 1989, 1991; Miao et al., 1991). Even in species where B chromosomes have been shown to have accumulation mechanisms, positive effects on fitness due to the presence of Bs may also contribute to their maintenance. 
We have previously described a situation in Allium schoenoprasum at the River Wye, Powys, U.K. where B chromosomes are present in high frequencies, and the pattern of distribution of the B-containing populations along the river suggests that they are spreading (Bougourd \& Parker, 1975, 1979b). In this species, there is no effective accumulation of B chromosomes (Bougourd \& Parker, 1979a and recent unpublished data). There is, however, clear evidence that B chromosomes can confer a selective advantage during the early stages of the life cycle. Studies carried out in the natural habitat have shown that B-containing individuals survive better than individuals without $\mathrm{B}$ chromosomes between the seed and seedling stages (Holmes \& Bougourd, 1989) and, in experimental populations, it has been demonstrated that B-containing individuals survive better during sowing and subsequent cultivation for several months under drought conditions (Holmes \& Bougourd, 1991). At the River Wye, the rocky crevices in which the plants grow are usually well above the river level during the summer months, and near-drought conditions prevail. However, the river can rise suddenly and dramatically, washing away ungerminated seeds or unanchored seedlings. Thus, prompt germination in limited moisture would seem to be highly advantageous in this habitat. The experiments described in this paper were designed to investigate the effects of B chromosomes on germination rate and on the ability of seeds to germinate in drought conditions.

\section{Materials and methods}

\section{Materials}

Eighteen thousand mature fruiting umbels were collected from a large population at the River Wye that had previously been shown to contain high frequencies of B-containing individuals (population 'B', Bougourd \& Parker, 1979b). Care was taken not to sample the same clone more than once. Individual umbels were placed in cellophane packets and, subsequently, three seeds were removed at random from each packet, one for each of the three experimental germination regimes.

\section{Seed characteristics}

Each seed was weighed individually on a Mettler AE163 electronic balance, and the area, maximum length, maximum breadth and perimeter of each seed was recorded using a Joyce-Loebl Magiscan image analyser, making sure that seeds were all placed on their convex surface to make comparisons more reliable.

\section{Germination experiments}

Germination experiments were carried out in a dark growth chamber at $20^{\circ} \mathrm{C}$ with 96 per cent relative humidity. Seeds were germinated in 96-well microtitre plates, with one seed in each of the inner 60 wells, avoiding the outer rows to minimize edge effects.

There were three experimental regimes: one 'normal' regime, in which each seed was given a plentiful supply of water $(100 \mu \mathrm{L})$, for comparisons of the B chromosome constitution of seeds with different germination rates and as a control for the drought regimes; and two drought regimes, one actual ('droplet') and one osmotic ('PEG'), to investigate the B chromosome constitution of seeds able to germinate in limited moisture. Both the droplet and PEG regimes were designed to induce a drought stress such that only 5 per cent of seeds were able to germinate. The volume of the water droplet given to each seed $(2 \mu \mathrm{L})$ and the concentration of polyethylene glycol $(0.085 \mathrm{~m}$ PEG $6000,100 \mu \mathrm{L}$ ) required to achieve this were determined in preliminary trials (data not presented).

Germination was scored every $4 \mathrm{~h}$ for the first 3 days, then every $12 \mathrm{~h}$ for the next 5 days, then every $24 \mathrm{~h}$ until germination was complete. A seed was considered to have germinated when the radicle could be seen protruding through the testa.

\section{Postgermination conditions}

Seedlings from the normal regime were transferred 5 days after germination into John Innes No, 2 'Gem' compost in individual compartments of 'Plantpak' plastic seed tray inserts. Seedlings from both drought regimes were transferred as soon as possible after germination into plentiful water in clean microtitre plates. Five days later, the survivors were potted into John Innes compost as described above.

\section{Chromosome counts}

The B chromosome constitution of seedlings was determined at mitotic metaphase in root tip cells. After 8 weeks, root tips were removed and pre-treated with 0.05 per cent $(\mathrm{w} / \mathrm{v})$ colchicine for $2 \frac{1}{2} \mathrm{~h}$, fixed in $1: 3(\mathrm{v} / \mathrm{v})$ acetic alcohol and stained by the Feulgen/orcein method.

\section{Results}

\section{Germination behaviour}

The germination behaviour of 18000 seeds in the normal watering regime is shown in Fig. 1. Germina- 


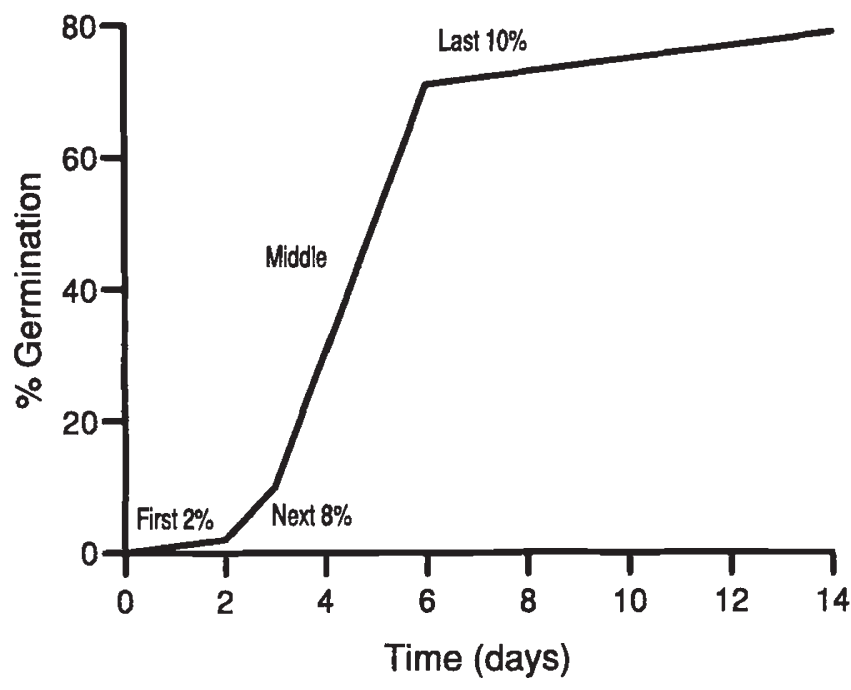

Fig. 1 Germination curve, showing the four germination groups (first 2 per cent, next 8 per cent, middle group, last 10 per cent). Eighteen thousand seeds were supplied with nonlimiting amounts of water in the dark at $20^{\circ} \mathrm{C}$.

tion began $12 \mathrm{~h}$ after the application of water and reached a maximum of nearly 80 per cent after 14 days, although most of the seeds ( 70 per cent) germinated within 7 days. Germinators were assigned to one of four groups: the first 2 per cent, the next 8 per cent, the middle group, and the last 10 per cent. All of the first 2 per cent, next 8 per cent and last 10 per cent of seedlings were potted on, together with 1000 seedlings taken at random from the middle group.

In the drought regimes, the percentages of germination attained were very close to those intended $(5$ per cent), with 5.1 per cent in the droplet regime and 5.4 per cent in the PEG regime. In the droplet regime, germination also began within the first day but stopped after the third day. Germination in the PEG regime did not begin until the twelfth day and stopped 5 days later. All germinators from the drought regimes were transferred to water as soon as possible. Most of the PEG germinators, but only 20 per cent of those germinating in the droplet regime, survived. This difference in behaviour between the two drought regimes is considered in the Discussion. All survivors were potted on.

\section{$B$ chromosome constitution of germinators}

(i) Normal watering regime. The percentages of seedlings with B chromosomes ( $+B$ ) in samples taken at random from each of the four germination groups, which represent different rates of germination in plentiful water, are given in Table 1, together with the
Table 1 The incidence of B chromosomes in the four germination groups in the normal watering regime

\begin{tabular}{lcccc}
\hline & First $2 \%$ & Next $8 \%$ & Middle & Last $10 \%$ \\
\hline No. of plants & 91 & 211 & 324 & 154 \\
$\%+$ B & 68 & 63 & 56 & 59 \\
Mean Bs per plant & 1.66 & 1.44 & 1.13 & 1.17 \\
Mean Bs per + B plant & 2.44 & 2.29 & 2.02 & 1.99 \\
\hline
\end{tabular}

mean numbers of Bs per plant and the mean numbers of Bs per B-containing plant.

The frequencies of $+B$ seedlings in each of the four germination groups were compared in a $4 \times 2$ contingency $\chi^{2}$ test, giving a $\chi_{|3|}^{2}$ value of $5.67(P \approx 0.1)$. Given that the categories are orthogonal, the overall $\chi^{2}$ was partitioned into three $2 \times 2$ contingency tests, and three component $\chi^{2}$ values were calculated using Kimball's formulae (Kimball, 1954). The results, given in Table 2, show that there is a significantly higher frequency of B chromosomes in seedlings from the two early germinating groups (first 2 per cent + next 8 per cent) compared with the middle germinating seedlings $\left(\chi_{[1]}^{2}=4.93, P<0.05\right)$.

The mean number of Bs per plant and the mean number of Bs per + B plant in the four groups were compared by one-way ANOvA after Anscombe transformation $(\sqrt{ }(x+3 / 8))$ (Table 3$)$. This is the best variance stabilizing transformation for distributions such as these which are highly positively skewed with the largest class the lowest and a low mean (Kendall \& Stuart, 1968). The mean number of Bs per plant for the four groups is significantly different $\left(F_{[3,776)}=3.53\right.$, $P<0.05)$ and a least significant difference test showed that this was due to a higher mean number of $\mathrm{Bs}$ in seedlings from the first 2 per cent group than in both the middle and last 10 per cent of germinators. The mean number of Bs per $+\mathrm{B}$ plant is not significantly different between the four groups $\left(F_{[3,463]}=1.71\right.$, $P>0.10)$.

(ii) Drought regimes. The percentages of seedlings with $\mathrm{B}$ chromosomes, the mean numbers of Bs per plant and the mean numbers of Bs per $+B$ plant in samples taken at random from both drought regimes are given in Table 4, together with values for a random control sample from the normal regime.

The frequencies of $+B$ seedlings in the drought samples were each compared with the random control sample from the normal regime in $2 \times 2$ contingency $\chi^{2}$ tests. Both the drought samples showed a significantly higher incidence of B-chromosomes than the control (droplet: $\chi_{[1]}^{2}=18.7, \quad P<0.001 ; \quad$ PEG: $\quad \chi_{[1]}^{2}=6.32$, 
$P<0.05)$. The mean numbers of Bs per plant and the mean numbers of Bs per $+B$ plant in the drought samples were compared with those of the control sample by $t$-tests (after Anscombe transformation as above). The mean number of Bs per plant was significantly higher in both drought samples than in the controls (droplet: $t=3.27, P<0.001$; PEG: $t=2.96$, $P<0.01)$. The mean number of Bs per $+\mathrm{B}$ plant was not significantly different between either of the drought samples and the control (droplet: $t=0.44, P>0.6$; PEG: $t=1.76, P>0.05)$.

(iii) Non-standard B-chromosomes. Eight different types of B chromosome were recorded in the seedling

Table 2 Partitioning of the overall $\chi^{2}$ to compare the frequencies of $+\mathrm{B}$ plants in the four germination groups in the normal watering regime

\begin{tabular}{lcc}
\hline \multicolumn{1}{c}{ Comparison of germination groups } & $\chi_{|1|}^{2}$ & $P$ \\
\hline First $2 \%$ vs. next $8 \%$ & 0.69 & $>0.20$ \\
First $2 \%+$ next $8 \%$ vs. middle & 4.93 & $<0.05$ \\
First $2 \%+$ next $8 \%+$ middle vs. last $10 \%$ & 0.05 & $>0.80$ \\
\hline
\end{tabular}

Table 3 Analysis of variance, after Anscombe tranformation, of the mean Bs per plant and the mean Bs per $+B$ plant in the four germination groups in the normal watering regime

\begin{tabular}{|c|c|c|c|c|c|}
\hline ANOVA & Source & d.f. & MS & $F$ & $P$ \\
\hline $\begin{array}{l}\text { Mean Bs } \\
\text { per plant }\end{array}$ & $\begin{array}{l}\text { Group } \\
\text { Residual } \\
\text { Total }\end{array}$ & $\begin{array}{r}3 \\
776 \\
779\end{array}$ & $\begin{array}{l}1.092 \\
0.310\end{array}$ & 3.53 & 0.015 \\
\hline $\begin{array}{r}\text { Mean Bs per } \\
+ \text { B plant }\end{array}$ & $\begin{array}{l}\text { Group } \\
\text { Residual } \\
\text { Total }\end{array}$ & $\begin{array}{r}3 \\
463 \\
466\end{array}$ & $\begin{array}{l}0.317 \\
0.185\end{array}$ & 1.71 & 0.164 \\
\hline
\end{tabular}

samples, all of which have been described previously (Bougourd \& Parker, 1975, 1979a; Holmes \& Bougourd, 1989). The percentages of standard and non-standard B-types in each of the samples are given in Table 5. Over 90 per cent of B chromosomes in all samples were the standard $\mathrm{B}^{\mathrm{t}-1}$. Of the non-standard types, almost 90 per cent were the metacentric $\mathrm{B}^{\mathrm{m}-1}$ thought to represent the isochromosome of $\mathrm{B}^{\mathrm{t}-1}$. Chisquared tests revealed no significant differences in the proportions of non-standard B chromosomes between any of the samples.

\section{B chromosomes and seed characteristics}

The means and 95 per cent confidence intervals of various seed characteristics for each $\mathrm{B}$ chromosome number class are given in Table 6 . These include the five characteristics measured directly (mass, area, width, length, perimeter) and three additional characteristics derived from them (squatness $=$ width/length, roundedness $=\operatorname{area}^{1 / 2} /$ perimeter, density $=$ mass $\left./ \operatorname{area}^{3 / 2}\right)$. There was considerable variation within each Bnumber class. $t$-tests to compare $0 \mathrm{~B}$ and pooled $+\mathrm{B}$ seeds, and one-way ANOvas to compare different B-number classes, revealed no significant differences. Regression analysis was performed for each seed characteristic on B-number. Only the regression of area on B-number was significant (area $=2.89+$ $\left.0.0162 \mathrm{~B} ; F_{\mid 1.1138\}}=4.26, P<0.05\right)$, but even in this case the $R^{2}$ value was very low $(0.4$ per cent $)$, implying that $B$-number is not a good predictor of seed area.

\section{Discussion}

The results presented here show that $\mathrm{B}$ chromosomes enhance both the rate of germination and the ability of seeds to germinate under drought conditions.

When water was freely available for germination, there was an increased frequency of B-containing individuals amongst the first 10 per cent of seeds to germinate compared with the middle germinating group ( 64 per cent cf. 56 per cent). The mean number of B chromosomes per seedling was also significantly

Table 4 The incidence of B chromosomes in a random sample of germinators in the two drought regimes (droplet and PEG) and the normal watering regime

\begin{tabular}{lccc}
\hline & Droplet & PEG & Normal watering regime \\
\cline { 2 - 4 } No. of plants & 108 & 278 & 434 \\
$\%+B$ & 79 & 65 & 56 \\
Mean Bs per plant & 1.53 & 1.47 & 1.15 \\
Mean Bs per + B plant & 1.95 & 2.26 & 2.03 \\
\hline
\end{tabular}


Table 5 The proportions of standard and non-standard B chromosome types in each germination group in the normal and drought regimes. The control for the drought regimes was a random sample of germinators in the normal watering regime

\begin{tabular}{lccc}
\hline & $\begin{array}{c}\text { Total number } \\
\text { of Bs }\end{array}$ & $\% B^{t-1}$ & $\begin{array}{c}\% \text { Non- } \\
\text { standard Bs }\end{array}$ \\
\hline First 2\% & 150 & 92 & 8 \\
Next $8 \%$ & 297 & 91 & 9 \\
Middle & 372 & 90 & 10 \\
Last 10\% & 184 & 91 & 9 \\
Droplet & 164 & 94 & 6 \\
PEG & 412 & 94 & 6 \\
Control & 489 & 91 & 9 \\
\hline
\end{tabular}

increased in these early germinators (1.48 cf. 1.13). When only B-containing seedlings were considered, there was also an increase in mean B-number $(2.32 \mathrm{cf}$. 2.02 ), but this was not significant. This implies that, although the early germinating group includes a higher frequency of B-containing seedlings, the seedlings do not carry a substantially increased number of $\mathrm{B}$ chromosomes.

In addition to these effects on germination rate, the results also indicate that seeds with $\mathrm{B}$ chromosomes have an enhanced ability to germinate in drought conditions. There was a significantly increased frequency of B-containing individuals amongst the 5 per cent of seeds that were able to germinate, both in the droplet experiment (79 per cent) and in the PEG experiment ( 65 per cent), compared with the control sample (56 per cent). The increase in B-frequency in the droplet sample was particularly dramatic, and the difference in the response to the two drought regimes may reflect differences in the way in which the drought was imposed. In the droplet experiment, $2 \mu \mathrm{L}$ of water was supplied to each seed, compared with $100 \mu \mathrm{L}$ given to the control seeds. In the PEG experiment, however, drought was osmotically imposed; here the amount of water available to each seed was precisely limited by the molarity of the polyethylene glycol solution. As explained above, the two sets of conditions were chosen so as to allow 5 per cent of seeds to germinate, as judged by the emergence of the radicle through the testa. Based on this criterion, very similar germination percentages were achieved in the droplet (5.1 per cent) and the PEG (5.4 per cent) experiments. However, many of the seeds scored as having germinated in the droplet sample failed to progress any further and represent 'false' germination. This occurs when moisture conditions are adequate to allow imbibition

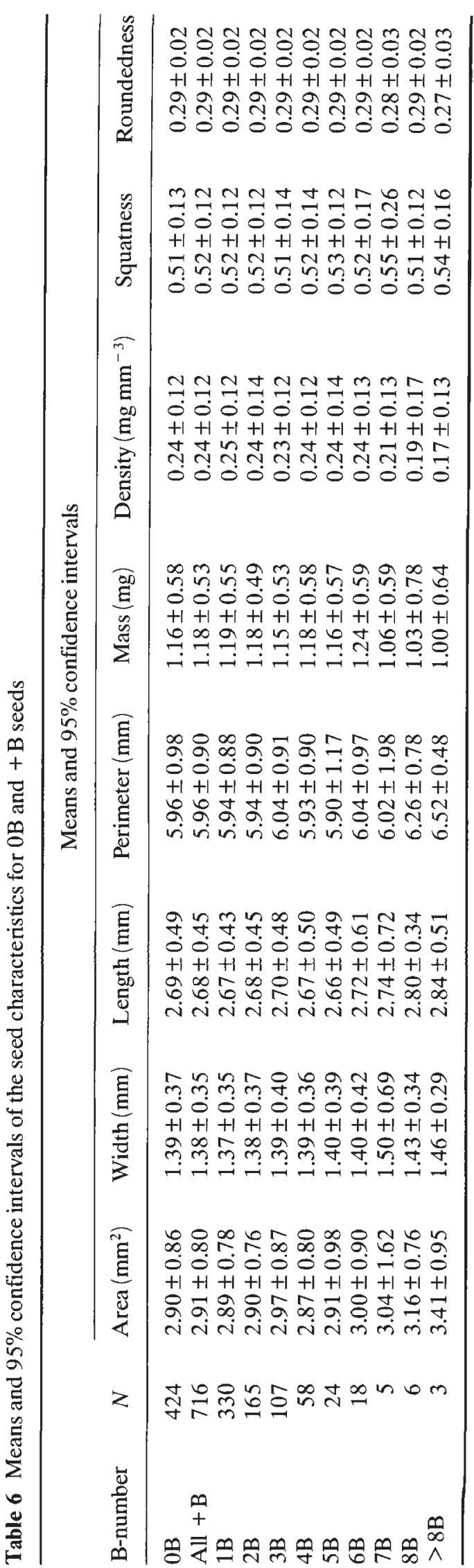


and cell elongation but not the initiation of cell division (e.g. Nutile \& Woodstock, 1967; Watt, 1974). The amount of true germination in the droplet sample, that is those seeds that were able to continue growing, was only about 1 per cent. Thus, the selection pressure imposed in the droplet experiment was considerably greater than that in the PEG experiment, and this may explain the greater response in terms of an increased frequency of B-containing individuals amongst the 'true' germinators in the droplet experiment.

In both the drought samples, the mean number of $\mathrm{B}$ chromosomes per seedling was significantly higher than in the control sample (droplet 1.53, PEG $1.47 \mathrm{cf}$. control 1.15). As for the early germinators in the normal regime, the increase in mean B-number was not significant when only B-containing seedlings were considered. Again this implies that, although there is a higher frequency of B-containing seeds amongst successful germinators in drought conditions, these B-containing seeds do not carry a substantially increased number of $\mathrm{B}$ chromosomes.

$\mathrm{B}$ chromosomes have been reported to increase the rate of germination in a number of other species, including Allium porrum (Vosa, 1966; Gray \& Thomas, 1985), Anthoxanthum alpinum (Rozmus, 1963) and Picea glauca (Teoh \& Rees, 1977). One problem with demonstrating the effects of B chromosomes on such a complex process as seed germination is that it is often difficult to distinguish them from the effects of other genetic and environmental influences. Ideally, one would examine the effects of B chromosomes in isogenic lines, but this is clearly impracticable for many species. In the present work, we have attempted to minimize genetic bias by analysing the effects of the Bs against a randomized genetic background; only one seed from each of 18000 different individuals was included in each germination regime. In addition, to minimize differential environmental influences, all seeds were harvested and stored under identical conditions.

Germination and seedling establishment are crucially important stages in any sexually reproducing plant population (Koller, 1972; Cook, 1979). Early germination may, under many circumstances, favour initial establishment, for example, by giving seedlings a competitive size advantage over slower germinators. Vosa (1966) suggested that this size advantage following faster germination was responsible for maintaining B chromosomes in cultivated populations of Allium porrum by unconscious selection by growers. In areas of scanty or erratic rainful it is claimed that faster germination can be a significant advantage, enabling seedlings to become established more rapidly and to make more efficient use of available resources (Sinha $e t$ al., 1982). For A. schoenoprasum in its riverside habitat, both rapid germination and the ability to germinate in limited moisture are likely to be beneficial, allowing seeds to take advantage of light falls of rain and to germinate promptly, thus increasing the likelihood of secure establishment before the river level rises. Certainly, there appears to have been strong selection for rapid germination in these populations, where seeds germinate much faster than those from other British, non-riverside populations (Bougourd, 1977). Levels of early mortality are high in this habitat, with only about 3 per cent of seeds surviving as seedlings after the first 2 months (Holmes, 1986). Previous work on natural populations has shown that B-containing individuals are more likely than individuals without Bs to survive this period; the frequency of B-containing individuals increased from 55 to 64 per cent between the seed and seedling stages (Holmes \& Bougourd, 1989). The increases observed in the present work in the frequency of B-containing seedlings in the earliest germinators and under the two drought regimes were comparable or greater, suggesting that the increased survival of B-containing individuals in natural populations could be due to the effects of $\mathrm{Bs}$ on germination behaviour.

How the $\mathrm{B}$ chromosomes influence germination behaviour is less clear. It is well known that the size and shape of seeds can influence germination rate and also the ability of seeds to germinate in dry conditions (Harper et al., 1970; Grime et al., 1981). In $A$. schoenoprasum, smaller, lighter, less dense seeds tend to have a reduced germination time and a greater ability to germinate in limited moisture (Plowman \& Bougourd, manuscript in preparation). We speculated previously (Holmes \& Bougourd, 1991) that seeds with B chromosomes may require less water for successful germination, and that this might arise through effects on seed size. In the present study, however, we have shown that there is no relationship between the presence of $\mathrm{B}$ chromosomes and seed size, seed density, or two aspects of seed shape (squatness and roundedness). Thus, it appears that differences in these seed characteristics do not provide an explanation of the effects of $\mathrm{B}$ chromosomes on germination. We are currently investigating other biochemical and physiological factors that are known to be involved in the germination process.

\section{Acknowledgements}

We are very grateful to Mr J. L. J. Jacquet for kindly allowing us access to the study area at the River Wye. We would also like to thank Dr T. J. Crawford for his 
statistical advice. We gratefully acknowledge the award of a studentship from NERC to ABP.

\section{References}

Bougourd, S. M. 1977. The Genetics and Cytology of Natural Populations of Allium schoenoprasum. Ph.D. Thesis, University of London.

BOUgOURD, S. M. AND PARKER, J. S. 1975. The B-chromosome system of Allium schoenoprasum I. B-distribution. Chromosoma, 53, 273-282.

BOUGOURD, s. M. AND PARKER, J. s. 1979a. The B-chromosome system of Allium schoenoprasum II. Stability, inheritance and phenotypic effects. Chromosoma, 75, 369-383.

BOUgOURD, S. M. AND PARKER, J. S. 1979b. The B-chromosome system of Allium schoenoprasum III. An abrupt change in B-frequency. Chromosoma, 75, 385-392.

COOK, R. E. 1979. Patterns of juvenile mortality and recruitment in plants. In: Solbrig, O. T., Jain, S., Johnson, G. B. and Raven, P. H. (eds) Topics in Plant Population Biology, pp. 207-231. Columbia University Press, New York.

DARLington, C. D. 1956. Chromosome Botany. Allen and Unwin, London.

FROST, s. 1958. Studies of the genetical effects of accessory chromosomes in Centaurea scabiosa. Hereditas, 44, 112-122.

GRAY, C. T. AND THOMAS, S. M. 1985. Germination and B chromosomes in Allium porrum L. J. Plant Physiol., 121, 281-285.

GREEN, D. M. 1990. Muller's ratchet and the evolution of supernumerary chromosomes. Genome, 33, 818-824.

GRIME, J. P., MASON, G., CURTIS, A. V., RODMAN, J., BARD, S. R., MOWFORTH, M. A. G., NEAL, A. M. AND SHAW, A. 1981. A comparative study of germination characteristics in a local flora. J. Ecol., 69, 1017-1059.

HÁKANSSON, A. 1954. Transmission of accessory chromosomes in Poa alpina. Hereditas, 40, 523-526.

HARPER, J. L., LOVELL, P. H. AND MOORE, K. G. 1970. The shapes and sizes of seeds. Ann. Rev. Ecol. Syst., 1, 327-356.

HIREMATH, S. C. AND MURTHY, H. N. 1986. The structure, stability and meiotic behaviour of B-chromosomes in Guizotia scabra (vis.) Chiov. ssp. scabra (Compositae). Caryologia, 39, 397-402.

HOLmES, D. S. 1986. Selection and Population Dynamics of B Chromosomes in Allium schoenoprasum. D. Phil. Thesis, University of York.

HOLMES, D. S. AND BOUGOURD, S. M. 1989. B-chromosome selection in Allium schoenoprasum. I. Natural populations. Heredity, 63, 83-87.

$\uparrow$ HOLMES, D. S. AND BOUGOURD, S. M. 1991. B-chromosome selection in Allium schoenoprasum II. Experimental populations. Heredity, 67, 117-122.
HUTCHINSON, J. 1975. Selection of B chromosomes in Secale cereale and Lolium perenne. Heredity, 34, 39-52.

JONES, R. N. 1975. B-chromosome systems of flowering plants and animal species. Int. Rev. Cytol., 40, 1-100.

JONES, R. N. 1985. Are B-chromosomes selfish? In: CavalierSmith, T. (ed.) The Evolution of Genome Size, pp. 397-425. Wiley, New York.

JONES, R. N. 1991. B-chromosome drive. Am. Nat., 137, 430-442.

JONES, R. N. AND REES, H. 1982. B Chromosomes. Academic Press, London.

KENDALL, M. G. AND STUART, A. 1968. Advanced Theory of Statistics, Vol. 3, 2nd edn. Griffin, London.

KIMBALL, A. w. 1954. Short-cut formulae for the exact partition of $\chi^{2}$ in contingency tables. Biometrics, 10, 452-458.

KOLLER, D. 1972. Environmental control of seed germination. In: Kozlowski, T. T. (ed.) Seed Biology vol. II, pp. 2-101. Academic Press, New York.

MIAO, v. P., COVERT, S. F. AND VAN ETTEN, H. D. 1991. A fungal gene for antibiotic resistance on a dispensable ("B") chromosome. Science, 254, 1773-1776.

NUTILE, G. E. AND woODSTOCK, L. W. 1967. The influence of dormancy-inducing dessication treatments on the respiration and germination of Sorghum. Physiologia Plantarum, 20, 554-561.

REES, H. AND HUTCHINSON, J. 1973. Nuclear DNA variation due to B chromosomes. Cold Spring Harb. Symp. Quant. Biol., 38, $175-182$.

Rozmus, M. 1963. Cytogenetical studies in biotypes of Anthoxanthum alpinum with accessory chromosomes. Acta Biologia Cracoviensia, 6, 115-141.

SINHA, A., GUPTA, S. R. AND RANA, R. S. 1982. Effects of osmotic tension and salt stress on germination of three grass species. Plant and Soil, 69, 13-19.

TEOH, S. B. AND JONES, R. N. 1978. B chromosome selection and fitness in rye. Heredity, 41, 35-48.

TEOH, S. B. AND REES, H. 1977. B chromosomes in White Spruce. Proc. R. Soc. Lond. Ser. B., 198, 325-344.

TEOH, S. B., REES, H. AND HUTCHINSON, J. 1976. B chromosome selection in Lolium. Heredity, 37, 207-213.

vosA, c. G. 1966. Seed germination and B-chromosomes in the leek (Allium porrum). Chromosomes Today, 1, 24-27.

WATT, L. A. 1974. The effect of water potential on the germination behaviour of several warm season grass species, with special reference to cracking black clay soils. J. Soil Cons. Ser. New South Wales, 30, 28-41.

\section{†Erratum}

In Holmes \& Bougourd (1991) there is an error on page 119 , right column, first line. It should state that nine (not none) of the thirteen different types of $B$ chromosome had been described previously. 